\title{
IPTU Verde: análise doutrinária e legislativa dos municípios de Jales, Santa Fé do Sul e Araçatuba
}

\section{Green IPTU: doctrinal and legislative analysis of Jales, Santa Fé do Sul and Araçatuba}

IPTU Verde: analisis doctrinaria y legislativa de las ciudades de Jales, Santa Fé do Sul y Araçatuba

Thalita Toffoli Páez ${ }^{1}$ Gisele Herbst Vazquez ${ }^{2}$

Luiz Sergio Vanzela ${ }^{3}$

${ }^{1}$ Aluna Regular do Programa de Cursos para Doutorado, na Universidad de Buenos Aires. Doutorado em andamento em Engenharia Biomédica e Mestrado Profissional em Ciências Ambientais, na Universidade Brasil, Campus Fernandópolis, SP. Professora Universitária na Universidade Brasil, campus Fernandópolis, SP. Graduação em Ciências Jurídicas e Sociais na Pontifícia Universidade Católica de Campinas.

E-mail: thalita.paez@ig.com.br

${ }^{2}$ Doutorado em Agronomia pela UNESP/Jaboticabal. Mestrado em Agronomia e graduação em Engenharia Agronômica pela USP/Piracicaba.

Professora da Universidade Brasil/Fernandópolis desde 1998, no Programa de Pós-Graduação em Ciências Ambientais, nível mestrado, e no curso de graduação em Agronomia. Em 2007, passou a integrar o Banco de Avaliadores do INEP-BASis. Conselheira titular do CREA/SP. E-mail: gisele-agro@uol.com.br

${ }^{3}$ Doutorado, mestrado e graduação em Agronomia pela UNESP-Ilha Solteira. Coordenador e Professor do Programa de Pós-Graduação Stricto Sensu em Ciências Ambientais da Universidade Brasil. Professor no Curso de Graduação em Agronomia da Universidade Brasil - Campus de Fernandópolis e no Curso de Graduação em Engenharia Ambiental e Sanitária da Fundação Educacional de Fernandópolis.

E-mail: Isvanzela@yahoo.com.br 
Resumo: O Estado organiza o comportamento dos indivíduos com a finalidade de alcançar o bem comum por meio do direito positivo, que, inicialmente, era empregado como forma de punição ou imposição de condutas. Porém, com o passar dos anos, o direito adquiriu nova feição, sendo o ser humano visto como o elemento central de todo o ordenamento, passando-se assim a premiar as condutas tidas como adequadas, dando origem ao chamado direito premial. Atualmente, no Brasil, dentro da área ambiental, esse método de estímulo de condutas desejadas vem sendo aplicado por intermédio do direito tributário dentro do âmbito urbano, por meio de incentivos fiscais, conhecidos como IPTU Verde (Imposto Predial e Territorial Urbano [IPTU]). Assim, o objetivo deste trabalho foi analisar os municípios mais populosos do noroeste paulista quanto a sua legislação ambiental. Concluiu-se que apenas Jales, Santa Fé do Sul e Araçatuba possuem lei neste sentido, porém com pouca eficácia social.

Palavras-chave: extrafiscalidade; preservação ambiental; desoneração tributária.

\begin{abstract}
The State organizes the citizens' behavior in order to achieve the common goal by the positive law, that at the beginning, was used as a form of punishment or imposition of conduct. However, the law acquired new feature, because nowadays the human being is seen as a central element of the whole system, for that reason began to reward behaviors considered appropriate, by a technique that is called prized law. Currently in Brazil, inside the environmental area, this method is used by the tax law applied within the urban context, through tax incentives, known as IPTU Verde (Imposto Predial e Territorial Urbano [IPTU]). The target of this work was to analyze the most populate cities in the northeastern São Paulo. Concluding, only the cities of Jales, Santa Fé do Sul and Araçatuba have law in that way, and it is little applied.
\end{abstract}

Key words: extrafiscality; environmental protection; tax relief.

Resumen: El Estado organiza el comportamiento de los ciudadanos con la finalidad de atender una finalidad social, por medio del derecho positivo, que inicialmente era usado como una forma de castigo o imposición de conducta. Sin embargo, con los años, el derecho adquirió nueva característica, porque el ser humano es visto como el centro de todo el sistema, y se empezó a premiar los comportamientos considerados apropiados, originando el llamado derecho premial. Actualmente en Brasil, en el área ambiental, se utiliza este método para estimular el comportamiento ambientalmente deseable a través de la ley tributaria aplicada en el contexto urbano, por medio de incentivos fiscales, conocidos como IPTU Verde (Imposto Predial e Territorial Urbano [IPTU]). El objetivo de este trabajo, es analizar las mayores ciudades del noreste de la provincia de São Paulo en cuanto a su legislación ambiental. Concluyéndose que solamente las ciudades de Jales, Santa Fé do Sul y Araçatuba, tienen una legislación al respecto, y con poca eficácia.

Palabras clave: extrafiscalidad; protección ambiental; reducción impuestos. 


\section{INTRODUÇÃO}

Estado é uma sociedade politicamente organizada que coordena os indivíduos para atingir as finalidades almejadas. Já o direito positivo objetiva a organização do comportamento humano, dentro de uma sociedade. Nesse sentido, a Constituição de um Estado traz o rol dos valores considerados mais importantes dentro de um certo contexto histórico, social, político e cultural.

A propriedade, a função social da propriedade e o meio ambiente ganharam status de direitos fundamentais dentro da República Federativa do Brasil. Sabe-se que o Estado possui necessidades arrecadatórias, para que consiga concretizar o bem comum, e utiliza-se de meios disponibilizados pelo direito positivo para satisfazê-las, através da previsão de tributos.

No Brasil, o imposto é uma das espécies tributárias, e a Constituição Federal outorga competência para que os entes federativos instituam os tributos especificamente previstos por ela.

De acordo com a previsão constitucional específica, ao Município é atribuída a competência para a criação do Imposto Predial e Territorial Urbano (IPTU), cuja hipótese de incidência é a propriedade, o domínio útil ou a posse de bem imóvel localizado em zona urbana municipal. Modernamente, o Estado preocupa-se que a instituição de tributos tenha uma função além da arrecadatória. Assim, o direito passa a ser pensado como um meio não apenas de inibir determinadas condutas, mas também de fomentar ações.

A concessão de benefícios fiscais àqueles que demonstram respeitar direitos fundamentais previstos na Constituição, pelas condutas objetivamente previstas em lei, pode ser premiada, servindo como instrumento de estímulo à população que, por falta de uma educação e consciência ambiental adequada, não tomariam determinadas medidas espontaneamente. 
Nesse sentido, a Constituição que outorgou competência aos municípios para a instituição do Imposto Predial e Territorial Urbano, também permitiu que este ente, através desse importante mecanismo, crie incentivos, na forma de descontos tributários, com a finalidade de estimular condutas ambientalmente desejadas.

A partir desse permissivo legal, o objetivo deste trabalho foi analisar a legislação dos municípios com população urbana superior a 20.000 (vinte mil) habitantes do noroeste paulista, quanto à instituição de incentivos tributários para os contribuintes do IPTU, que observando critérios estabelecidos pela norma, tivessem implantado no âmbito de seus imóveis urbanos medidas ambientalmente adequadas. A esse incentivo deu-se o nome de "IPTU Verde".

\section{REVISÃO BIBLIOGRÁFICA}

\subsection{Estado e Direito}

Estado é uma sociedade politicamente organizada, que tem por objetivo coordenar seus indivíduos com o intuito de alcançar determinada finalidade, impondo os meios desejados (DALLARI, 2009).

Portanto ao Estado incumbe a satisfação do bem comum, ou seja, garantir e favorecer o desenvolvimento de cada ser humano como ser dotado de dignidade. $\mathrm{O}$ direito positivo surge como instrumento do Estado para auxiliá-lo a organizar e planificar o comportamento humano de determinada sociedade, tendo em vista uma finalidade comum, que, por fim, será o fruto de uma escolha política, influenciada por fatores históricos, sociais, culturais e temporais.

Assim, o direito posto passou a ser utilizado como o meio hábil para alcançar o bem comum de certa sociedade. E o Estado, por meio de seus representantes, é quem vai determinar quais serão as necessidades públicas a serem perseguidas. 
Elencadas as finalidades sociais ou bem comum de dada sociedade, cumpre ao Estado buscar medidas para satisfazê-las, o que se dá, inclusive, pela atividade arrecadatória, momento no qual o Estado se utiliza de suas receitas originárias e derivadas para concretizar o bem comum.

\subsubsection{Direitos fundamentais}

Direitos fundamentais são direitos próprios e imanentes dos seres humanos que Ihes são garantidos pela positivação em determinado ordenamento, com a tarefa de propiciar aos homens todos os meios para o exercício de uma vida digna. A despeito da aparente facilidade de conceituação, a problemática se identifica quanto ao seu alcance, que é mutável, e a tarefa de delimitá-lo depende da análise histórica e social de um povo.

Percebe-se que, ao longo do tempo, os direitos fundamentais vêm se ampliando, tendo em vista as características e as necessidades de determinado povo, dentro de certo contexto histórico, concluindo-se que o rol dos direitos fundamentais não é homogêneo e tampouco coincidente no curso da história (MENDES; COELHO; BRANCO, 2007).

$\mathrm{Na}$ atualidade, tendo em vista todo o cenário de destruição da fauna e flora e a crescente preocupação com o próprio futuro da humanidade, o meio ambiente é visto com fator primordial para a manutenção da vida de todos os seres existentes no planeta.

Dada à crescente preocupação ambiental, é possível falar-se no direito fundamental a um meio ambiente saudável e equilibrado, observando-se a construção de um rol de direitos fundamentais, inerentes aos seres humanos, como medidas aptas ao exercício da vida digna, inclusive no que tange ao direito de propriedade, principalmente em face da conjugação desse direito ao exercício de uma função social. 


\subsubsection{Direito de Propriedade}

A propriedade é um direito complexo, que atribui ao seu titular poderes sobre o bem, quais sejam gozar, usar, dispor e reivindicar. Ademais, esse poder é exercível sobre todos e, em princípio, é pleno, pois em regra o proprietário concentra todos os atributos em suas próprias mãos.

Pode-se afirmar que a propriedade é uma relação entre o seu titular, o proprietário, e a coletividade, já que todos os demais sujeitos devem respeitar esse direito, nos termos da própria Constituição Federal (TAVARES, 2009).

No ordenamento jurídico brasileiro, o direito à propriedade imobiliária nasce a partir do registro, e com a tradição no que se refere aos móveis. Assim, a propriedade é direito fundamental, pois, com a constituição da propriedade, o ser humano pode atender suas necessidades básicas, fundamentais ao exercício de uma vida digna.

\subsubsection{Constituição Federal e o Direito de Propriedade}

A Constituição Federal de 1988, em seu artigo 5ํ, inciso XXII, garante o direito de propriedade e, no inciso XXIII, diz que a propriedade deve atender uma função social (BRASIL, 1988). O direito de propriedade passa a ser considerado um direito fundamental, pois inserido está no ordenamento jurídico brasileiro, no rol dos direitos e garantias fundamentais.

É certo que este direito continua a estruturar-se em torno dos atributos que lhes são próprios. Além disso, o ordenamento brasileiro submete o direito de propriedade ao exercício de uma função social.

Claro que é também por meio da propriedade que se faz possível a preservação do patrimônio do sujeito, passível de lhe promover o mínimo existencial, do qual o homem, muitas vezes, retira seu próprio 
IPTU Verde: análise doutrinária e legislativa dos municípios de Jales, Santa Fé do Sul e Araçatuba

sustento, para viver dignamente. Assim, ser proprietário é essencial para o resguardo dos direitos da personalidade.

\subsubsection{Função social da propriedade}

Importante destacar que os institutos jurídicos devem ser analisados tanto sob o enfoque de sua estrutura, como também no de sua função. Com a propriedade essa averiguação se impõe, tanto que a própria Constituição Federal, em seu artigo 5으, incisos XXII e $X X I I I$, foi expressa ao determinar serem direitos fundamentais, tanto a propriedade, como a sua função social (BRASIL, 1988).

Ora, além da estrutura, ou seja, da definição do direito de propriedade, deve-se verificar qual a função do instituto. Nesse sentido, a Constituição Federal, além de declarar expressamente que a propriedade deve ter uma função, afirmou que essa finalidade deve ser, além de tudo, social.

A função social da propriedade urbana se considera cumprida quando os seres humanos conseguem se desenvolver nesse meio, através do exercício de direitos fundamentais, como a moradia, trabalho, circulação, lazer, integração entre os sujeitos, crescimento educacional e cultural, preservação do meio ambiente etc., sem se olvidar das normas estabelecidas pelo Estatuto da Cidade e do Plano Diretor, quando houver (RAMOS, 2011).

Assim sendo, a propriedade, com todos seus elementos constitutivos, passa a satisfazer não somente os interesses individualistas do proprietário, mas também serve como instrumento para a satisfação social.

\subsubsection{Código Civil e a propriedade}

O Código Civil, em respeito à Constituição Federal de 1988 (BRASIL, 1988), reconhece o direito de propriedade e, para isso, o 
subordina ao exercício de uma função social, em seu artigo 1228 (BRASIL, 2002). A propriedade passa a não ser vista somente sob a ótica individualista, mas principalmente sob a perspectiva coletiva, como instrumento para a satisfação de valores de maior valor.

A propriedade que se exerce por meio de seus atributos, não significa ao proprietário um direito amplo e irrestrito, pois a própria coletividade é um limite ao direito de propriedade. Sustenta-se que a propriedade encontra limites nas próprias normas de ordem pública.

O ordenamento jurídico brasileiro exige para a existência do direito de propriedade a soma de todos os atributos somados a um título, que é o registro, nos termos do artigo 1227 do Código Civil (BRASIL, 2002). Sendo a coletividade um limite próprio ao direito de propriedade, resta claro que o proprietário não pode abusar do seu direito sob pena de não cumprir a função social do seu bem. Assim sendo, ao direito de propriedade é conjugada uma série de imposições e vedações, que são justificadas pelo prisma coletivo que é dado ao instituto.

Portanto a propriedade, dentro do prisma civil, passa a ser vista como um direito complexo, que, além da conjugação de seus atributos, deve cumprir uma função social, que inclui, de forma prioritária, a necessidade de respeito, preservação e recuperação ao meio ambiente, bem jurídico de titularidade de todos.

Destaca-se que o dever de respeito, preservação e recuperação do meio ambiente, no que tange às propriedades, é considerado por muitos como verdadeiras obrigações, que teriam origem no direito pessoal, mas que decorreriam de uma relação com um direito real, no caso, a propriedade.

No entanto, sob o ponto de vista dos direitos fundamentais, sequer se faz necessário imiscuir-se no plano do direito obrigacional para se extrair as proibições de intervenção e os imperativos de proteção, que são imanentes dos direitos fundamentais e deles decorrem. 
Assim, de acordo com o explicitado, tanto a propriedade, como a função social, quanto ao meio ambiente saudável, são direitos fundamentais no âmbito da República Federativa do Brasil. Todos esses direitos fundamentais devem ser compreendidos como formas de proibições de intervenções danosas na propriedade, e também como normas impositivas ao proprietário, do dever de proteger sua propriedade, dando-Ihe uma função social com a preservação de um meio ambiente saudável.

\subsubsection{Estatuto da Cidade: tributação como instrumento da política urbana}

A Constituição Federal é expressa ao afirmar no "Art. 182, A política de desenvolvimento urbano, executada pelo Poder Público municipal, conforme diretrizes gerais fixadas em lei, tem por objetivo ordenar o pleno desenvolvimento das funções sociais da cidade e garantir o bem-estar de seus habitantes" (BRASIL, 1988).

O Poder Constituinte de 1988 disciplinou a cidade como bem de uso comum, articulando a vida humana com o meio ambiente artificial, ou seja, com o espaço construído e as necessidades das pessoas em determinado território. Além disso, criou orientação jurídica de forma a estruturar a política de desenvolvimento urbano com dois objetivos principais: o pleno desenvolvimento das funções sociais das cidades e o bem-estar de seus habitantes (RAMOS, 2011).

A Lei 10.257/2001, que instituiu o Estatuto da Cidade, prevê, em seu Capitulo II, quais deverão ser os instrumentos de política urbana que poderão ser utilizados pelos municípios, com a finalidade de atingir os objetivos constitucionais propostos (BRASIL, 2001).

Observa-se que, expressamente a tributação, nos termos do Estatuto da Cidade, em especial o IPTU, é prevista como instrumento de política urbana, para fomento de atividades sustentáveis que envolvam a propriedade, posse ou domínio útil de propriedade urbana. 


\subsection{Conceito de meio ambiente}

O meio ambiente é formado por uma conjunção de fatores que interagem entre si, e que deve ser equilibrado para que possa garantir a vida dos seres existentes no planeta. Nesse sentido, Silva (2005) menciona que o meio ambiente é a conjugação dos elementos naturais, artificiais e culturais, aptos a propiciar uma vida equilibrada, em todas as suas formas.

Portanto observa-se que o conceito de meio ambiente é amplo, abrangendo elementos que lhes são inerentes, a saber, natural, artificial, cultural e do trabalho. Entende-se como meio ambiente natural os elementos que Ihe estão naturalmente ligados, como é o ar, solo, fauna, flora, subsolo, água, atmosfera e biodiversidade (BELCHIOR, 2011).

O meio ambiental artificial é aquele que nasce por obra dos seres humanos, da sua engenhosidade. Hoje, com facilidade, pode-se visualizar o meio ambiente artificial, por intermédio dos próprios centros urbanos. Porém, mesmo desde os primórdios da humanidade, já se verifica que o engenho humano, mesmo que rudimentar, é capaz de criar um meio ambiente artificial.

Já o meio ambiente cultural, que também decorre de obra do ser humano, tem como peculiaridade o fato de esse engenho se dirigir a alguma finalidade, seja histórica, paisagística, artística, turística, arqueológica, espeleológica ou cultural.

E por último, há o meio ambiente do trabalho, que corresponde "ao local onde se desenvolve boa parte da vida do trabalhador, cuja qualidade de vida está, por conseguinte, em íntima vinculação com a qualidade daquele ambiente" (BELCHIOR, 2011).

Assim sendo, a interação de todos esses elementos, forma aquilo que é conhecido como meio ambiente, como elemento imprescindível à vida dos seres humanos. 


\subsubsection{Meio ambiente no Direito Positivo Brasileiro}

A própria Constituição Federal da República Federativa do Brasil trata do meio ambiente em diversas passagens, porém a parte mais relevante é aquela prevista no Título VIII, em seu Capítulo VI, intitulado "Do Meio Ambiente" (BRASIL, 1988).

Assim, o artigo 225 da Constituição Federal diz ser direito de todos o meio ambiente equilibrado, que é elemento necessário à sadia qualidade de vida, afirmando por fim, ser dever de todos, sua busca e proteção (BRASIL, 1988). Já a lei 6.938/81 (BRASIL, 1981), que trata da Política Nacional do Meio Ambiente, prevê em seu artigo 3으, I, o conceito de meio ambiente, nos seguintes termos: "entende-se por I- meio ambiente, o conjunto de condições, leis, influências e interações de ordem física, química e biológica, que permite, abriga e rege a vida em todas as suas formas".

Portanto o legislador pátrio previu o meio ambiente como um bem jurídico complexo, composto pelos elementos inerentes ao meio ambiente natural, meio ambiente do artificial, meio ambiente cultural e meio ambiente do trabalho, fatores esses que devem interagir para formar um todo equilibrado.

\subsubsection{Competência para preservação e proteção ambiental}

A Constituição Federal prevê em seu artigo 23, incisos VI e VII, a competência comum da União, Estados, Munícipios e Distrito Federal para preservar e proteger o meio ambiente, ação esta que deve ser realizada em conjunto com a coletividade (FARIA, 2014).

Todos os entes federativos devem promover a proteção ambiental e, portanto, fomentar condutas ambientalmente adequadas. Nesse sentido, nota-se que a própria função arrecadatória do Estado pode ser utilizada por qualquer dos seus entes, para estimular condutas que promovam uma função socioambiental a determinados institutos de 
direito privado, seja inibindo a poluição, seja promovendo a reparação e preservação do meio ambiente.

Assim, o Estado, como pessoa jurídica de direito público interno, pode, por meio de seus entes federativos, criar medidas de estímulos, perante seus cidadãos, de modo a promover medidas socioambientais, de forma conjunta, nos termos dos artigos constitucionais explicitados. Trata-se de dar eficácia à previsão constitucional, que demanda a atuação conjunta do Poder Público, com seus administrados.

A despeito da previsão constitucional do artigo 23, essa Carta também se preocupou em distribuir as competências para a instituição de tributos entre os entes federativos, prevendo, em cada situação, o ente responsável pela criação, bem como a hipótese de incidência que permite a instituição tributária.

Portanto a Constituição Federal explicita sua nítida preocupação ambiental, a qual demanda uma atuação conjunta entre Poder Público e Iniciativa Privada, que devem se conciliar, com a finalidade de promover a manutenção da vida digna de todos os seres que vivem sobre o planeta.

\subsection{Direito Tributário}

Hoje o Estado é entendido como social e de direito. Social, pois, dentre as suas finalidades principais, está a preocupação com o ser humano, que é detentor de direitos fundamentais. E de Direito, pois o Estado edita as normas para serem cumpridas pelos particulares e por si mesma.

O Direito Tributário é o ramo do Direito que nasceu para fazer jus à necessidade arrecadatória do Estado para a consecução do bem comum. Atualmente verifica-se uma necessidade crescente do Estado em aumentar suas receitas, e o principal motivo surge do fato de que o Estado passou a ser o responsável por inúmeras obrigações frente 
IPTU Verde: análise doutrinária e legislativa dos municípios de Jales, Santa Fé do Sul e Araçatuba

aos seus cidadãos, como por exemplo, a saúde, que, na República Federativa do Brasil, é universal.

O Direito Tributário pode ser utilizado como instrumento para a realização de políticas públicas do Estado, utilizando-se da criação de incentivos tributários. Porém tais benefícios somente terão as consequências sociais desejadas se forem fruto de um estudo econômico e jurídico, em conjunto, acerca das repercussões do incentivo criado.

Dentro da metodologia jurídica atual, existe espaço para técnicas que auxiliam o jurista a identificar, prever e explicar as consequências sociais de escolhas políticas imbuídas em legislações (ex ante) e decisões judiciais (ex post). A proposta mais promissora nesse sentido é a Análise Econômica do Direito (AED), bastando que se compreenda sua metodologia e limitações. Porém, para seu uso correto, é necessário um preparo adequado de juristas e economistas, fato esse inexistente na situação atual do ensino superior brasileiro (GICO JUNIOR, 2009).

Quando da criação de determinado estímulo tributário, é necessária a análise dos custos associados a esse benefício. No caso em questão, é imprescindível que se verifiquem os custos para a implementação das medidas previstas em lei, como autorizadoras do desconto, e também dos valores que deixarão de ser arrecadados, em virtude do benefício concedido pela Administração Pública, para que se identifique a viabilidade do instituto.

O direito tem duas dimensões, a) a abstrata, constituída pelo sistema de normas jurídicas e princípios, e b) a concreta, na qual se verifica a efetividade das normas jurídicas. Normalmente somente a dimensão abstrata é levada em consideração, o que é errôneo, visto que a boa interpretação não pode deixar de considerar aspectos práticos em relação à concretização e funcionalização do direito, tanto para as partes quanto para a sociedade, de forma a mensurar os custos sociais (CORREIA; MENDES, 2013). 
No Brasil, a Constituição Federal, lei máxima do ordenamento jurídico, previu diversas hipóteses de incidência tributárias, e permitiu que seus entes federativos instituíssem as espécies tributárias, seguindo as orientações constitucionais. Assim, caso haja permissivo constitucional para a instituição de determinado tributo, o ente federativo competente pode fazê-lo. Com a instituição do tributo, nasce uma norma jurídica geral e abstrata, que prevê uma hipótese de incidência. Acontecido um fato que se enquadre na descrição da norma, nasce a obrigação tributária.

\subsubsection{Direito Premial}

A partir da criação de um rol de direitos fundamentais amplos, orientados à proteção da dignidade da pessoa humana e tudo mais que lhe seja pertinente, surge a necessidade de adaptação do direito à realidade.

O meio ambiente surge como direito fundamental, pois imprescindível à preservação da própria vida humana. À necessidade do desenvolvimento sustentável, são criadas normas sancionatórias punitivas que tem pôr fim a punição daqueles que poluem, degradam ou não recompõem o meio ambiente, mas também outras normas são criadas com o fim de premiar aqueles que estão de acordo com as prerrogativas ambientais.

Observa-se que, hoje em dia, o direito está pensado para ser instrumento eficaz, a serviço da pessoa humana. Ademais, a função promocional do direito tem por finalidade determinar atuações esperadas, tornando essas ações atraentes ao sujeito (DANTAS, 2014).

A razão da criação dessas leis que premiam, surge do fato de que as atitudes voluntárias de preservação e resguardo ambiental não são comuns. Sabe-se que, somente com uma população consciente dos problemas ambientais e engajada, é que as condutas desejadas 
IPTU Verde: análise doutrinária e legislativa dos municípios de Jales, Santa Fé do Sul e Araçatuba

poderiam ser espontâneas. No entanto, para tanto, necessário seria um trabalho de estímulo à educação ambiental, na base da formação do ser humano.

O ser humano que aprende o porquê da necessidade de preservação do meio ambiente é capaz de apresentar condutas espontâneas tendentes ao resguardo ambiental. Porém, diante de uma realidade falha, em que a educação ambiental não é prioridade, outros instrumentos têm que ser criados, para estimular os sujeitos a agirem de maneira ambientalmente correta.

Um desses instrumentos é o estímulo fiscal, no qual o ente estatal, responsável pela criação de determinado tributo, legisla, prevendo situações que, se cumpridas pelos cidadãos, serão premiadas através de descontos tributários.

Em um sistema jurídico, pode-se tanto desencorajar a fazer quanto encorajar a não fazer. Muitas normas reforçadas por sanções negativas são na verdade normas positivas, podendo ocorrer quatro situações: a) comandos reforçados por prêmios; b) comandos reforçados por castigos; c) proibições reforçadas por prêmios; d) proibições reforçadas por castigos (GORON, 2015).

Assim, o legislador vem criando "estímulos" de diversas ordens, aos cidadãos, para fomentar atitudes ecologicamente adequadas, tendo em vista a falta de uma política de educação ambiental eficaz.

\subsubsection{Imposto Predial e Territorial Urbano}

O Imposto Predial e Territorial Urbano (IPTU) é tributo previsto na Constituição Federal, em seu artigo 156, inciso I, e sua instituição é de competência municipal e tem como hipótese de incidência o fato de ser proprietário, ter o domínio útil ou ser possuidor de propriedade predial e territorial urbana (BRASIL, 1988).

O conceito do IPTU está pressuposto, na Constituição, como a exteriorização de riqueza hábil a ensejar a tributação, e se baseia 
no conceito empregado pela teoria geral do direito, de que só é propriedade o direito que abarca as faculdades de usar, gozar e dispor (PALSEN, 2009).

Para a compreensão desse tributo, necessário se faz a análise conjunta do artigo 156, inciso I, §1으, I e II, e 182,§4으, II, da Constituição Federal (BRASIL, 1988); dos artigos 32 a 34 do Código Tributário Nacional, do Código Civil e do Estatuto da Cidade (BRASIL, 1966).

A propriedade é o direito real que atribui ao seu titular as faculdades de usar, gozar, dispor e reaver o bem, conforme já preceituado.

No entanto existem situações específicas, em que, instituídos certos direitos reais, seus titulares são também capazes de revelar riqueza, motivo pelo qual também podem ser considerados como sujeitos ativos do IPTU, tais como o usufrutuário e o promitente comprador de imóvel, quando o compromisso for irretratável, e o compromissário houver pago todas as parcelas de sua dívida, e portanto, já pode lavrar escritura ou propor ação de adjudicação compulsória (PAULSEN, 2009).

Já o conceito de imóvel encontra-se regido pelo Código Civil (BRASIL, 2002), que estabelece em seu artigo “Art. 79: São bens imóveis o solo e tudo quanto se lhe incorporar natural ou artificialmente".

Por sua vez, é o Código Tributário Nacional que define zona urbana para efeito da instituição do IPTU, em seu artigo 32, §§1으 e 2으, dizendo:

$\S 1$ 을 Para os efeitos deste imposto, entende-se como zona urbana a definida em lei municipal; observado o requisito mínimo da existência de melhoramentos indicados em pelo menos 2 (dois) dos incisos seguintes, construídos ou mantidos pelo Poder Público:

I- meio-fio ou calçamento, com canalização de águas pluviais; II- abastecimento de água;

III- sistema de esgotos sanitários;

IV- rede de iluminação pública, com ou sem posteamento para distribuição domiciliar; 
V- escola primária ou posto de saúde a uma distância máxima de 3 (três) quilômetros do imóvel considerado.

$\S 2$ ㅇ A lei municipal pode considerar urbanas as áreas urbanizáveis, ou de expansão urbana, constantes de loteamentos aprovados pelos órgãos competentes, destinados à habitação, à indústria ou ao comércio, mesmo que localizados fora das zonas definidas nos termos do parágrafo anterior.

Assim sendo, a Constituição Federal permite que os Municípios instituam o IPTU e, somente com a edição da lei municipal, é que tal tributo será instituído, sendo certo que, com a ocorrência do fato gerador, é que haverá subsunção do fato à norma, autorizadora da cobrança do referido tributo.

\subsubsection{Dedução do IPTU como instrumento de estímulo}

Um dos principais instrumentos de estímulo ambiental é o desconto fiscal concedido por alguns Municípios àqueles que comprovem a instituição de determinados mecanismos de interesse ambiental em suas residências.

Trata-se de um prêmio ofertado pelo Município àquele que desenvolve atitudes ambientais almejadas por esse ente federativo.

Conforme mencionado, o município tem competência para instituir o IPTU, nos termos do artigo 156 da Constituição Federal (BRASIL, 1988). Ademais, quando o Município detém a competência para instituir, também possui a competência para isentar e, conforme o caso, premiar.

É o legislador quem estabelece se certa hipótese é tributável ou não, pois vige no direito tributário o princípio da legalidade. Se determinar por lei infraconstitucional que o fato não é tributável, estar-se-á diante de uma isenção, se o realizar por norma constitucional, é caso de imunidade (COÊLHO, 2002).

Assim, o Município passa a se utilizar da técnica da extrafiscalidade tributária, concedendo prêmios, promoções, descontos em 
tributos para atingir metas ambientais e promover medidas ambientalmente desejadas, visando atingir uma finalidade coletiva ambiental, posto que a incidência ou não do tributo é avaliada a partir de outras políticas, que não a meramente arrecadatória. Observa-se, portanto, que o IPTU tanto pode servir como um instrumento de arrecadação do Município, como também um instrumento de estímulo aos munícipes, para que estes pratiquem determinadas condutas, sendo, no caso em comento, em benefício do meio ambiente.

\section{MATERIAL E MÉTODOS}

Este trabalho baseou-se em pesquisa documental em fontes oficiais analisando a legislação dos municípios de São José do Rio Preto, Catanduva, Votuporanga, Fernandópolis, Mirassol, Olímpia, José Bonifácio, Novo Horizonte, Araçatuba, Jales e Santa Fé do Sul, que, localizados no noroeste paulista, possuem a maior população urbana.

Também foram feitas consultas pela internet, bem como presencial, nas Prefeituras Municipais e nas Secretarias responsáveis pela tributação municipal.

A pesquisa logrou encontrar três municípios em que o benefício fiscal denominado "IPTU Verde" foi instituído, a saber, Araçatuba, Jales e Santa Fé do Sul. No tocante a estes municípios foram coletados dados documentais inerentes à legislação, bem como as relacionadas ao número de contribuintes que aderiram ao incentivo.

\section{RESULTADOS E DISCUSSÃO}

\subsection{Município de Araçatuba e a Lei Municipal 7.423/2011}

Araçatuba é um município paulista com uma população estimada em 2015 de 192.757 habitantes (IBGE, 2015). Em 2011 foi aprovada a Lei 7.423/2011, que "Dispõe sobre o programa de incentivo 
IPTU Verde: análise doutrinária e legislativa dos municípios de Jales, Santa Fé do Sul e Araçatuba

ao desconto de IPTU, denominado IPTU Sustentável" (ARAÇATUBA, 2011).

Essa lei, em seu artigo 1으, menciona o seu objetivo de "fomentar medidas que preservem, protejam e recuperem o meio ambiente, mediante concessão de benefício tributário ao contribuinte".

Interessante observar que o parágrafo 3 o da referida lei menciona o quantum de desconto a ser fornecido ao contribuinte, o que depende da análise de qual das medidas elencadas pelo parágrafo único do artigo 1 o foram preenchidas.

Nesse sentido:

Art. 3o O benefício tributário no Imposto Predial e Territorial Urbano (IPTU) para o caso das medidas dispostas no art. 1.으 será concedido nas seguintes proporções: I- $2 \%$ para as medidas descritas nos incisos I, II e VI; 11-4\% para a medida descrita no inciso III e IV; III- 6\% para a medida descrita no inciso V Parágrafo único. Os benefícios podem ser cumulados. Art. 4응 Os interessados em obter o beneficio tributário devem protocolar o pedido e sua justificativa no órgão competente, até a data de 31 de agosto do ano anterior em que deseja o desconto tributário, contendo a medida que aplicou em sua edificação ou terreno, instruindo o mesmo com documentos comprobatórios.

Art. 5ㅇ O incentivo fiscal desta lei apenas será concedido aos contribuintes quites com suas obrigações tributárias para com o Município.

Ademais se permite que os benefícios sejam acumulados, estimulando que os munícipes preencham o maior número possível medidas ambientalmente desejadas.

A despeito da iniciativa trazida pela lei, segundo o dirigente administrativo Sérgio Clóvis Novais, da Divisão de Tributação da Prefeitura de Araçatuba, em 2015 somente foram protocolizados 6 pedidos de dedução do IPTU com base nas medidas ambientais relacionadas à lei 7.423/2011 (ARAÇATUBA, 2011). 
No município de Araçatuba, a lei 7.423/2011 ainda não ganhou a notoriedade devida, tanto que a sua adesão vem sendo muito pequena (ARAÇATUBA, 2011). Nota-se que falta um trabalho de educação e divulgação ambiental municipal, de forma a conscientizar a população em todos os âmbitos, sobre a premente necessidade de preservação/ recomposição do meio ambiente.

Além da falta de informação do contribuinte e da questão de educação ambiental, a implementação de medidas que possam garantir benefícios fiscais, em geral, são custosas, o que leva o contribuinte a sopesar o custo versus o benefício financeiro.

Uma solução para a questão poderia ser dada por meio de subsídios para a implementação das medidas ambientais propostas no artigo 1 ㅇ da Lei 7.423/2011, para que essa lei produzisse os efeitos desejados (ARAÇATUBA, 2011).

\subsection{Município de Jales e a Lei $3.686 / 2003$}

O município de Jales, localizado no noroeste paulista, teve sua população estimada em 48.922 habitantes no ano de 2015 (IBGE, 2015).

Em 2003, foi aprovada a lei 3.686, que "autoriza a redução do Imposto Predial e Territorial Urbano (IPTU) e Imposto Territorial Urbano (ITU), aos proprietários de lotes edificados e não edificados que adotem medidas que estimulem a proteção, preservação e recuperação do meio ambiente", tendo caráter notório de estímulo ambiental (JALES, 2003).

Inclusive o parágrafo 1 을 dessa lei, de maneira expressa, declara o seu objetivo de fomento às atividades de proteção, preservação e recuperação do meio ambiente, o qual se reproduz:

$\S 10$ As medidas adotadas deverão ser:

I - Lotes Edificados, inclusive condomínios horizontais e verticais: 
- Sistema de captação da água de chuva;

- Sistema de Reúso de água;

- Sistema de aquecimento hidráulico solar;

- Sistema de aquecimento elétrico solar;

- Construções com material sustentável;

- Utilização de energia passiva;

- Que contenham arborização no calçamento.

Conforme os dados fornecidos pela Prefeitura Municipal de Jales, foram concedidos 116 benefícios fiscais, no tocante à redução do IPTU, com base na legislação mencionada, no último exercício. Observa-se, portanto, nesse município, uma maior adesão comparativamente a Araçatuba à disposição da lei, o que, provavelmente, é fruto de uma população mais bem informada.

\subsection{Município de Santa Fé do Sul e a Lei 2.422/2007}

Santa Fé do Sul é um munícipio paulista com população estimada em 31.348 mil habitantes, no ano de 2015 (IBGE, 2015). Este município possui previsão legislativa hábil a conferir descontos "no valor do Imposto Predial e Territorial Urbano- IPTU aos proprietários ou responsáveis que adotarem medidas de prevenção, preservação e conservação do meio ambiente", conforme a Lei 2.422/2007 (SANTA FÉ DO SUL, 2007).

Por intermédio dessas deduções maiores, os contribuintes são estimulados a adotar as medidas previstas em lei, pois, mesmo com eventual custo para a implementação das medidas elencadas no art. 1ำ a médio e longo prazo, os custos são amortizados, e o contribuinte passa a desfrutar de uma situação de vantagem econômica.

$\mathrm{O}$ artigo 1 ㅇ desta lei menciona:

Art. 10- Fica o Poder Executivo autorizado a conceder benefício tributário na forma de desconto no valor do Imposto Predial e Territorial Urbano - IPTU aos proprietários ou responsáveis 
pelo tributo do imóvel no qual se adote isolada ou conjuntamente uma das seguintes medidas de prevenção, preservação e conservação do meio ambiente:

I- uso de energia solar;

II- conservação da permeabilidade do solo;

III- aproveitamento das águas pluviais;

IV- reuso de águas;

$\checkmark$ - promoção do saneamento ambiental;

VI- proteção de espécies arbóreas nativas;

VII- conservação dos remanescentes florestais e bosques; e VIII- casos especiais de proteção da flora.

Assim, com a política de concessão de descontos maiores, um elevado número de prédios foi beneficiado, totalizando 201 imóveis quanto ao desconto do IPTU, o que é significativo, levando-se em consideração o número de habitantes deste município.

\section{CONSIDERAÇÕES FINAIS}

O direito de propriedade saiu do enfoque individualista e patrimonialista para uma perspectiva coletiva. A propriedade não deve satisfazer apenas ao indivíduo, mas também à sociedade como um todo.

Ademais, admite-se que os direitos fundamentais devem ser observados tanto nas relações dos particulares com o Estado, como nas relações onde estão somente albergados particulares, dando-se uma eficácia horizontal aos direitos fundamentais.

A Constituição Federal foi contundente ao exigir do proprietário o exercício de uma utilidade coletiva para o seu bem, ao condicionar o exercício da função social ao respeito ambiental, e prever como bem de todos o meio ambiente saudável. Para efetivar suas disposições, a Carta Constitucional inclusive previu que a não consecução de uma finalidade social, poderá acarretar o despojamento da propriedade.

A codificação civil com respeito à previsão constitucional associa a propriedade ao exercício de uma função social, elenca seus 
atributos e agrega a necessidade de registro para que se opere sua aquisição. À luz de todas as evoluções sofridas, a propriedade passou a ser considerada como um direito fundamental, necessário para se lograr o mínimo existencial, e consequentemente a vida digna.

Também como fundamental, passou-se a conceber o meio ambiente saudável, de modo que propriedade com função social e meio ambiente saudável são direitos, todos fundamentais, que devem ser conciliados e fomentados, o que ocorre, também, pela implementação de medidas fiscais.

Observa-se a grande preocupação ambiental dentro da ótica do direito de propriedade, tanto que, a despeito das imposições e limites próprios aos direitos fundamentais, a legislação infraconstitucional também se encarrega de criar limitações, para que a propriedade se conforme e respeite a coletividade, principalmente diante da necessária preservação, recomposição e prevenção ambientais, que representam a utilidade social do bem.

O Estado utiliza-se do Direito para fomentar condutas desejadas em benefício do bem comum. Nesse sentido, o Estado cria tributos com o fim arrecadatório ou tendo em vista outros objetivos, que sejam constitucionalmente estimulados. A Constituição Federal prevê como fundamentais os direitos à propriedade e a função social da propriedade, somente justificando-se a primeira, caso respeitada a segunda.

Ademais, também essa Carta permite ao ente federativo Município que este institua um tributo, chamado Imposto Predial e Territorial Urbano (IPTU), cuja hipótese de incidência se funda justamente no fato de se ter a propriedade, o domínio útil ou ser possuidor de propriedade predial e territorial urbana. Nota-se claramente a finalidade arrecadatória do IPTU, no entanto, o Direito evoluiu não apenas para sancionar as condutas socialmente reprováveis, mas também como forma de criar estímulos e condutas socialmente esperadas. 
Nesse sentido, diversos municípios têm previsto descontos tributários decorrentes do IPTU, prevendo que, se o contribuinte comprovar a adoção de uma série de medidas, que devem estar objetivamente estabelecidas em lei, como consequência, há o recebimento de um desconto no débito decorrente do tributo.

Após análise de 11 municípios na região noroeste do Estado de São Paulo, a saber, Jales, Santa Fé do Sul, Novo Horizonte, Catanduva, Mirassol, São José do Rio Preto, Votuporanga, Araçatuba, Fernandópolis, Olímpia e José Bonifácio quanto à existência de descontos no IPTU em virtude de medidas ambientais adotadas pelos contribuintes, somente os municípios de Jales, Santa Fé do Sul e Araçatuba, possuem, até a data da realização deste trabalho, previsão legislativa nesse sentido.

Nota-se uma carência legislativa preocupante, posto hoje ser o direito premial, consubstanciado, nesse caso específico, por meio de descontos tributários do IPTU, um importante instrumento posto à disposição do Estado, apto a perseguir condutas fomentadas.

Interessante alternativa seria aquela adotada pelas políticas de educação ambiental, dado ao fato que a população que não é ambientalmente educada e informada, acaba por não ter interesse na tomada de medidas protetivas do meio ambiente.

Assim, a divulgação, a educação, o estímulo financeiro, dado também por descontos tributários, mostram-se como meios importantes de proteção ambiental, tendo em vista que, hoje, tais tomadas de posições são imprescindíveis para o exercício de importantes direitos fundamentais, tais como a propriedade, a função social da propriedade, e o meio ambiente saudável, e consequentemente, para a própria manutenção da vida neste planeta. 
IPTU Verde: análise doutrinária e legislativa dos municípios de Jales, Santa Fé do Sul e Araçatuba

\section{REFERÊNCIAS}

ARAÇATUBA, Cidade [de]. Lei n. 7423/2011. Dispõe sobre o programa de incentivo ao desconto de IPTU, denominado IPTU Sustentável. Disponível em: <http://www.camaraaracatuba.com.br/site/legislacao/legislacao.asp>. Acesso em: 16 nov. 2016.

BELCHIOR, Germana Parente Neiva. Hermenêutica jurídica ambiental. São Paulo: Saraiva, 2011.

BRASIL. Lei n. 10.406, de 10 de janeiro de 2002. Institui o Código Civil. Diário Oficial da União, de 11 jan. 2002. Disponível em: <http://www.planalto.gov. br/ccivil_03/leis/2002/L10406.htm>. Acesso em: 6 nov. 2016.

. Lei n. 10.257, de 10 de julho 2001. Regulamenta os arts. 182 e 183 da Constituição Federal, estabelece diretrizes gerais da política urbana e dá outras providências. Diário Oficial da União, de 11 jul. 2001. Disponível em: <http://www.planalto.gov.br/ccivil_03/leis/LEIS_2001/L10257.htm>. Acesso em: 2 nov. 2016.

. Constituição da República Federativa do Brasil, de 5 de outubro de 1988. Diário Oficial da União, Presidência da República, Brasília, DF, 5 out. 1988. 103 p. Disponível em: <https://www.planalto.gov.br/ccivil_03/ constituicao/constituicao.htm>. Acesso em: 8 dez. 2016.

. Lei n. 6.968, de 31 de agosto de 1981. Dispõe sobre a Política Nacional do Meio Ambiente, seus fins e mecanismos de formulação e aplicação, e dá outras providências. Diário Oficial da União, de 2 set. 1981. Disponível em: <http://www.planalto.gov.br/ccivil_03/leis/L6938.htm>. Acesso em: 2 nov. 2016.

. Lei n. 5.172, de 25 de outubro de 1966. Dispõe sobre o Sistema Tributário Nacional e institui normas gerais de direito tributário aplicáveis à União, Estados e Municípios. Diário Oficial da União, de 27 out. 1966. Disponível em: <https://www.planalto.gov.br/ccivil_03/leis/L5172.htm>. Acesso em: 3 nov. 2016.

COÊLHO, Sacha Calmon Navarro. Curso de direito tributário brasileiro: (comentários à Constituição e ao Código Tributário Nacional, artigo por artigo). Rio de Janeiro: Forense, 2002.

CORREIA, Cecília Barbosa Macêdo; MENDES, Dany Rafael Fonseca. Teoria econômica aplicada ao processo civil brasileiro. Revista de Informação 
Legislativa, ano 50, n. 197, jan./mar. 2013. Disponível em: <https:// www2.senado.leg.br/bdsf/bitstream/handle/id/496984/000991340. pdf?sequence=1>. Acesso em: 10 jun. 2017.

DALLARI, Dalmo de Abreu. Elementos de Teoria Geral do Estado. 28. ed. São Paulo: Saraiva, 2009. 314 p.

DANTAS, Gisane Tourinho. IPTU Verde e o direito à cidade sustentável. Revista do Programa de Pós-Graduação em Direito da Universidade Federal da Bahia, Salvador, v. 24, n. 26, 2014.

FARIA, Ana Luisa Sousa. Tributo verde: "o IPTU e a tributação indutora como instrumento para o desenvolvimento sustentável". 1. ed. Curitiba: Appris, 2014.

GICO JUNIOR, Ivo Teixeira. Notas sobre a análise econômica do Direito e Epistemologia do Direito. In: CONGRESSO NACIONAL DO CONPEDI, 18., São Paulo, 4-7 nov. 2009. Anais... São Paulo: CONPEDI. Disponível em: <http://www.publicadireito.com.br/conpedi/manaus/arquivos/anais/ sao_paulo/2662.pdf>. Acesso em: 1ํo jun. 2017.

GORON, Henrique Sampaio. Sanção Premial, Normas Indutoras e a Extrafiscalidade Tributária. Revista Páginas de Direito, Porto Alegre, ano 15, n. 1271, 10 ago. 2015. Disponível em: <http://www.tex.pro.br/index.php/ artigos/316-artigos-ago-2015/7328-sancao-premial-normas-indutoras-e-aextrafiscalidade-tributaria>. Acesso em: 20 jun. 2016.

INSTITUTO BRASILEIRO DE GEOGRAFIA E ESTATÍSTICA (IBGE). Cidades@. 2015. Disponível em: <http://cidades.ibge.gov.br/painel/painel. php?codmun=350280>. Acesso em: 3 nov. 2016.

JALES, Cidade [de]. Lei n. 3.686/2003. Lei que autoriza a redução do Imposto Predial e Territorial Urbano - IPTU e Imposto Territorial Urbano - ITU, aos proprietários de lotes edificados e não edificados que adotem medidas que estimulem a proteção, preservação e recuperação do meio ambiente. Disponível em: <http://consulta.siscam.com.br/camarajales/ arquivo?id=24776> . Acesso em: 16 nov. 2016.

MENDES, Gilmar Ferreira; COELHO, Inocêncio Mártires; BRANCO, Paulo Gustavo Gonet. Curso de Direito Constitucional. São Paulo: Saraiva, 2007.

PALSEN, Leandro; MELO, José Eduardo Soares de. Impostos federais, estaduais e municipais. 5. ed., rev. e atual. Porto Alegre: Livraria do Advogado Editora, 2009. 
IPTU Verde: análise doutrinária e legislativa dos municípios de Jales, Santa Fé do Sul e Araçatuba

RAMOS, José Eduardo Silvério. Tributação ambiental: o IPTU e o meio ambiente urbano, 2011.

SANTA FE DO SUL, Cidade [de]. Lei n. 2.422, de 30 de agosto de 2007. Lei que autoriza o Poder Executivo a conceder benefício tributário na forma de desconto do Imposto Predial e Territorial Urbano - IPTU aos proprietários ou responsáveis que adotarem medidas de prevenção, preservação e conservação do meio ambiente. Disponível em: <https://leismunicipais. com.br/a/sp/s/santa-fe-do-sul/lei-ordinaria/2007/243/2422/lei-ordinaria-n2422-2007-autoriza-o-poder-executivo-a-conceder-beneficio-tributario-naforma-de-desconto-no-valor-do-imposto-predial-e-territorial-urbano-iptuaos-proprietarios-ou-responsaveis-que-adotarem-medidas-de-prevencaopreservacao-e-conservacao-do-meio-ambiente?q=2422>. Acesso em: 16 nov. 2016.

SILVA, Jose Afonso. Curso de Direito Constitucional Positivo. 24. ed., rev. e atual. São Paulo: Editora Malheiros, 2005.

TAVARES, André Ramos. Curso de Direito Constitucional. 7. ed. São Paulo: Saraiva, 2009. 
